\title{
El problema de la generación del Estado en Spinoza (contractualismo y naturalismo en la teoría política de la modernidad temprana) ${ }^{1}$ \\ The Case of the Generation of the State in Spinoza (Contractualism and Naturalism in Early Modern Political Philosophy)
}

\author{
Juan Vicente Cortés Cuadra
}

Universidad Diego Portales / Universidad Alberto Hurtado, Santiago, Chile.

\begin{abstract}
RESUMEN. El presente artículo busca determinar un modelo propiamente spinociano para pensar la generación del Estado descrita en el Tratado Politico. Para ello se intenta desvincular el modelo utilizado por Spinoza del modelo contractualista (estado de naturaleza/pacto social/estado de civilidad), bajo el cual ha sido habitualmente pensado (incluso cuando se sostiene que es un modelo naturalista). Comenzaremos por identificar el "campo de presencia" sobre el cual tanto Hobbes como Spinoza se sitúan. Este será caracterizado bajo el rótulo general de "aristotelismo político", intentando mostrar su ambigüedad fundamental, constitutiva del problema que tanto Hobbes como Spinoza buscan resolver. Luego, haremos un examen detallado del modelo por el cual Spinoza responde a dicho problema.
\end{abstract}

Palabras clave: Spinoza; contractualismo; naturalismo; aristotelismo político; pensamiento político de la modernidad temprana.
Abstract. This paper deals with the determination of the spinozistic model on the generation of the State described in the Political Treatise. To achieve this purpose we must separate the Spinoza's model from the contractualistic one, for the former is usually conceived by means of the latter (even when commentators conceive it as a naturalistic model). In the first part, we will identify the "presence's field" on which both Hobbes and Spinoza are thinking. This field, which entails a fundamental ambiguity, will be characterized as the "political aristotelianism". Then, we will proceed to a detail examination of the model by which Spinoza built an answer to this problematic ambiguity.

Key words: Naturalism; Contractualism; Political Aristotelianism; Early Modern's political thought. 
El modelo habitual utilizado para explicar la generación del Estado (imperium) en Spinoza es de tipo hobbesiano ${ }^{2}$. Es sabido que este modelo se articula según tres momentos: ficción del estado de pura naturaleza determinado por el derecho natural / ficción del pacto social por el que se determina la generación del estado de civilidad / ficción de la persona del soberano según el derecho civil. El debate en torno a la interpretación de la filosofía política de Spinoza (¿se trata o no de una forma de contractualismo?) que opuso a dos importantes comentadores de la política spinociana, Alexandre Matheron y Douglas Den Uyl, supone de hecho este modelo como matriz interpretativa fundamental ${ }^{3}$. Es cierto que, mientras Den Uyl ve en Spinoza a un continuador del contractualismo hobbesiano, Matheron cree poder distinguir una diferencia que desmarcaría a Spinoza de Hobbes. ¿Cuál es esta diferencia? Spinoza procedería a una sustitución: el estado de civilidad se deduciría del estado de naturaleza a partir, no ya de la ficción del pacto social, sino de la sola mecánica de las pasiones. Y es que, según Matheron, el estado de naturaleza sería para Spinoza el lugar ficticio en el cual, de la sola mecánica de las pasiones individuales, se seguiría un afecto común que tendría como resultado la generación del Estado. Así, en su importante obra Individu et communauté chez Spinoza, Matheron hace de esta ficción el momento propiamente spinocista de la construcción del concepto de Estado. Ahora bien, desde este punto de vista, el modelo "naturalista" de Spinoza se distinguiría del modelo contractualista de Hobbes únicamente por el contenido de los elementos que lo constituyen, pero no por su forma o estructura. Lo anterior no sería problemático si pudiésemos encontrar un texto en el que Spinoza estableciera esta "génesis pasional". Sin embargo, el problema se plantea precisamente al reconocer que dicho momento está "ausente" del proceso de construcción de la definición del Estado -es decir que hay un vacío o laguna en el texto del Tratado político en el que cabría esperar su formulación- ${ }^{4}$.

En el presente artículo nos esforzaremos en determinar un modelo propiamente spinociano para la comprensión de la generación del Estado. Creemos, en efecto, que es posible considerar el capítulo II del Tratado político, en el que Spinoza procede a la deducción de la generación del Estado, como un texto completo. Por el contrario, si a algunos les ha parecido que el texto estaba incompleto, creemos que esto se debe justamente a que se le considera a partir de un modelo que supuestamente habría de seguir. Es necesario, para entender la singularidad del modelo spinociano, resituarlo en su contexto filosófico -lo que implica, pero no se reduce a una confrontación con la obra de Hobbes-. En efecto, creemos que, tanto el contractualismo de Hobbes como el naturalismo de Spinoza, constituyeron dos soluciones antagónicas, propias de la filosofía política de la modernidad temprana, a una problemática común. Por ello, hemos creído necesario determinar los a priori históricos que condicionaron el campo sobre el cual Hobbes y Spinoza 
posicionaron sus modelos 5 . De modo que nuestro trabajo se organizará naturalmente en dos secciones: primero intentaremos describir el "campo de presencia", determinado bajo la figura del "aristotelismo político", sobre el cual Hobbes y Spinoza se instalan y frente al cual también se posicionan. Intentaremos luego determinar el dispositivo o modelo teórico mediante el cual Spinoza cuestiona y responde al campo de presencia en el que interviene, privilegiando el estudio del capítulo II del Tratado político. De esta forma, esperamos por una parte determinar la singularidad del movimiento conceptual que nos lleva a la definición spinociana del imperium a partir de la "potencia de la multitud", y, por la otra, contribuir a una necesaria revisión de ciertas categorías fundamentales para la historia de la filosofía política moderna.

1. "Aristotelismo político": condiciones de la teoría política a fines del siglo XVI

Comenzaremos haciendo una breve mención a la crítica que hace Hobbes a la concepción "griega" de la idea del hombre como zoon politikòn al comienzo de su De Cive, pues esta nos da una visión privilegiada del "campo de presencia" de la filosofía política de los siglos XVI y $\mathrm{XVII}^{6}$. Contrariamente a la lectura de algunos comentadores, que ven en el aristotelismo político "pre-hobbesiano" una doctrina naturalista de la política contra la que Hobbes se hubiese rebelado, creemos que el filósofo inglés da cuenta de una lectura mucho más sutil de la teoría política de su tiempo ${ }^{7}$. Según Hobbes, en efecto, "la mayor parte de los hombres que han escrito algo sobre los asuntos públicos [respublicae/commonwelth] suponen, piden o postulan que el hombre es un animal que nace apto para la sociedad"8. Esto es precisamente lo que "los griegos llamaban un zoon politikon", concepto que significa, según Hobbes que "las causas por las que los hombres se reúnen y disfrutan de una sociedad mutua" son "por naturaleza", es decir necesarias". Ahora bien, lo extraño (al menos para un lector acostumbrado a las oposiciones rígidas) es lo que sigue, a saber que es justamente este prejuicio el que les hace creer que los fundamentos de la teoría política no requieren sino "que los hombres concuerden sobre un cierto número de pactos y cláusulas que luego llaman leyes"10. Dicho de otra forma: puesto que el hombre es por naturaleza apto para la sociedad, basta con que convengan y pacten sobre el mejor modo de vivir en común para formar una Civitas. La crítica de Hobbes está lejos de ser la crítica a un naturalismo "historicista". Hobbes no está discutiendo en el plano de los hechos, de la historia, es decir, no está criticando la descripción de la formación histórica de las sociedades políticas. Su crítica va dirigida contra los principios explicativos propuestos por el "aristotelismo político" de su época para dar cuenta del hecho del Estado. Y esta crítica apunta al uso de dos principios que, para un lector desatento, pueden parecer contradictorios: uno referente a la naturaleza humana (el hombre es un animal político); el otro referente al origen de la sociedad (la sociedad política proviene de una o un cierto número convenciones). Pero, ¿no es parte Hobbes 
de aquellos que creen que una "convención" origina la Civitas?

Para entender la crítica que hace Hobbes de estos dos principios, es necesario remitir a otro texto del De Cive, en el que el filósofo critica la noción de ley concebida por el pseudo-Aristóteles en la Retórica a Alejandro (obra que tanto Hobbes como todos sus contemporáneos atribuían erróneamente al estagirita ${ }^{11}$ ). Hobbes cita un texto del prefacio a la Retórica en el que la ley es definida como "un discurso definido en conformidad al consentimiento común del Estado (civitas; City), y que declara cómo se debe actuar en cada caso"12. Esta cita es dada como ejemplo de aquellos que confunden ley y pacto (pactum/covenant), en la medida en que creen que "las leyes no son sino ómologémata [i.e. convenciones], es decir reglas de vida determinadas por el consentimiento común de los hombres"13. Esta definición de la ley, dice Hobbes, no puede ser una definición general, puesto que no comprende ni la ley divina ni la ley natural, limitándose a la sola ley civil. Pero incluso en este caso es ilegítima, puesto que se funda en un concepto errado de la Civitas. En efecto, parece preguntar Hobbes: ¿qué significa el "común consentimiento de la Civitas"? Es evidente que si se habla de un "común consentimiento" es porque la Civitas está siendo entendida no como una persona civil dotada de una voluntad singular, sino como "una multitud de hombres que declaran por consentimiento común (por ejemplo, un texto ratificado por votos), ciertas reglas de vida"14. Ahora bien, esta concepción del Estado, que está a la base de la confusión entre pacto y ley, implica el doble error antes señalado: pretende que los hombres se unen por naturaleza según una serie de pactos formando así la Civitas. La verdadera distinción entre pacto y ley depende de la verdadera comprensión de lo que es la Civitas, la que supone a su vez la verdadera comprensión de la naturaleza humana. Un pacto, nos dice Hobbes, es una promesa por la que los pactantes se obligan mutuamente a algo; pero esta obligación es un puro deber cuyo cumplimiento, si no se le agrega nada, quedará a la merced de los pactantes. La ley civil en cambio es el mandato que obliga a cumplir ese deber, y su fuerza de coerción proviene del miedo a la pena establecida en caso contrario. La ley es un mandato o prescripción cuyo principio (es decir, el fundamento de la obediencia u obligación) reside únicamente en la voluntad de la persona del soberano, es decir de la persona civil formada por el pacto de sumisión de la voluntad de cada cual a la voluntad de uno solo (hombre o asamblea que queda fuera del pacto), pacto por el que se realiza la unión de las voluntades requerida para la obtención de la paz y de la seguridad, y que implica que todos transfieren el derecho sobre sus fuerzas y facultades a ese hombre o asamblea, con el fin de constituir un poder soberano capaz "por el terror", de "conformar las voluntades individuales a la unidad y a la concordia"15. Así, para Hobbes la confusión del aristotelismo es doble: con respecto a la naturaleza del hombre y con respecto al fundamento jurídico del statum civilis.

Con lo anterior, Hobbes nos revela sin embargo lo que puede ser considerado como la ambigüedad propia del aris- 
totelismo político de fines del siglo XVI y comienzos del XVII. La interpretación de la teoría política de Aristóteles como un naturalismo suele fundarse en el comienzo de la Politica. Al comienzo del primer libro, Aristóteles aborda el origen de la Polis desde dos puntos de vista distintos. Desde el punto de vista de su formación histórica, el origen son las familias que se reúnen en aldeas, y las aldeas que se reúnen en una Polis ${ }^{16}$. Pero desde el punto de vista de la explicación física, la causa es la Polis misma en tanto que causa final de la reunión de los hombres, puesto que es el fin en el que se realiza la naturaleza humana ${ }^{17}$. A la pregunta ¿por qué los hombres viven en familia? Aristóteles no dirá: "el hombre es un animal político", sino por una necesidad "biológica". En efecto, "es necesario que se emparejen los que no pueden existir uno sin el otro, como la hembra y el macho en vistas a la generación (y esto no en virtud de una decisión, sino como en los demás animales y plantas; es natural la tendencia a dejar tras de sí otro ser semejante a uno mismo) y como el que manda y el que obedece, y esto por naturaleza, para la seguridad de ambos" ${ }^{\prime 18}$. Es a causa de unas de estas insuficiencias inscritas en su naturaleza que el ser humano tiende naturalmente a unirse a otros. Por el contrario, la politicidad natural del hombre se manifiesta sólo una vez que la Polis se ha formado, puesto que es en la Polis (como todo) que el individuo (como parte) encuentra su verdadera función y definición ${ }^{19}$. La Polis realiza la autosuficiencia a la que el hombre tiende naturalmente por su in- suficiencia, y se plantea así como la causa final de las diferentes formas de unión de los seres humanos, de modo que es gracias a ella que puede explicarse el proceso histórico de la formación de las Ciudades existentes. El hombre es un animal político porque es en la Polis que puede realizar su naturaleza ${ }^{20}$. Ahora bien, Aristóteles hará una precisión extraña: luego de afirmar que mediante el lenguaje los seres humanos son capaces de comunicarse los unos a los otros, tanto lo justo como lo injusto, estableciendo así una comunidad de valores, condición de toda comunidad, familiar o política, y por lo mismo, medio por el que parece realizarse la politicidad del hombre, escribe que "el primero que la estableció [sc. la Polis] fue causa del mayor de los bienes" ${ }^{21}$. Como lo va a mostrar el Libro II de la Política, la politeia es de las Ciudades existentes es siempre la obra de un legislador - lo que parece introducir una ruptura en la formación natural de la Polis. Ahora bien, este quiebre del naturalismo que parece existir en la teoría de Aristóteles fue intensificado por la lectura, al comienzo de la modernidad, de la Retórica a Alejandro y de la doctrina de la ley como regla indicando la forma de vivir, mediante la cual podría ser realizado el vivir bien.

De esta forma, antes de la intervención de Hobbes en la escena de la teoría política, el aristotelismo en la scientia civilis se desarrolló según dos inflexiones distintas. En efecto, es posible distinguir, en el marco del (o de los) aristotelismo(s) político(s) de los siglos XVI y comienzos del XVII, dos grandes tendencias para la 
explicación de la aparición del Estado: una "convencionalista", que tiende a dar a la doctrina del pacto un rol preponderante en la concepción del origen de la comunidad política (respublica), y la otra "naturalista", que considera la comunidad política como el resultado de un serie de determinaciones naturales ${ }^{22}$. En efecto, lo que era considerado un medio en los textos aristotélicos, será para los "convencionalistas", como bien lo diagnostica Hobbes, la causa de la instauración de un orden político. Lo que era por el contrario mero origen histórico en Aristóteles, dará cuenta, para los "naturalistas", de la explicación causal de la formación del Estado. Ejemplos de la tradición del "convencionalismo" o contractualismo aristotélico pueden hallarse sobre todo en los autores "monarcómacos", como Junius Brutus, pseudónimo del autor del panfleto hugonote Vindicae contra Tyrannos de $1579^{23}$, pero también entre los juristas como Hugo de Groot (1543-1645), con su De jure belli ac paci de $1625^{24}$, y los teólogos como Francisco Suárez (1548-1617), con su De legibus de $1612^{25}$. Por el contrario, otros teólogos como Francisco de Vitoria (1484-1546), con sus Relecciones sobre el poder politico $(1528)^{26}$ o juristas que despliegan todo un sistema cosmológico-jurídico como Jean Bodin (1529/30-1596), con sus Six Livres de la République $\left(1576,{ }^{2} 1583\right)^{27}$ tienden hacia una concepción naturalista de la formación de la sociedad política.

Pero es necesario hacer dos precisiones. Primero, que ambos aristotelismos surgen de un proceso de contaminación, al ser interpretados en el contexto del Oc- cidente latino y cristiano. De suerte que, por una parte, el contractualismo aristotélico es en realidad el resultado de una doble lectura, a la vez teológica y jurídica, de la Política de Aristóteles, en la que el modelo jurídico (romano) de la asociación entre pares libremente unidos por un contrato, heredado del Digesto y utilizada luego por el movimiento comunitarito del bajo Medio $\mathrm{Evo}^{28}$, será combinado o bien con el modelo teológico (judeo-cristiano) de la "alianza", heredado de las Sagradas Escrituras, o bien con el modelo del vasallaje desarrollado hacia el fin del Imperio romano y que predominó durante todo el alto Medio $\mathrm{Evo}^{29}$. Por otra parte, el naturalismo aristotélico será articulado 1 / a la historia (ya sea a la historia política, de las instituciones, ya sea a la historia sagrada de la salvación), 2/ al uso de la jurisprudencia (e incluso de la etimología, en los casos de Bodin o de Loyseau) y 3/ a una jerarquía cósmica de clara ascendencia neoplatónica ${ }^{30}$. Segundo, es de notar que ambas tendencias doctrinales contenían elementos que uno esperaría encontrar más bien en la tendencia contraria. Así por ejemplo, autores "convencionalistas" como Grocio o Junius Brutus aceptan la idea de una sociabilidad natural del hombre. Los naturalistas por su parte están lejos de ser "naturalistas radicales". Siguiendo una observación de Jean Terrel, hay que recordar que para Vitoria la naturaleza no forma por sí misma las "ciudades"; lo único que hace es "sugerir" al hombre la comunidad política para resolver el problema de su conservación ${ }^{31}$. Ciertamente, Dios es la causa eficiente de las repúblicas ${ }^{32}$. Pero esto 
no significa que los hombres hayan sido creados por Dios en repúblicas ${ }^{33}$. Son los hombres los que construyen, mediante el establecimiento de leyes, este tipo de asociaciones. $Y$ es que convencionalismo y naturalismo no eran dos escuelas claramente definidas, sino que constituían el terreno común del aristotelismo, el que las implicaba en tanto que tendencias, pero sin que la una eliminara nunca totalmente a la otra. Hobbes lo diagnosticó de manera convincente para el convencionalismo aristotélico; pero el caso del naturalismo es simétrico.

Pero, si no se trata de escuelas, esto no quiere decir que no hubiera tradiciones identificables a partir de problemas y conceptos comunes, sino simplemente que éstas tenían otros modos de repartición. Se puede distinguir al menos cuatro tradiciones o discursos de la política anteriores a Hobbes: el discurso del derecho natural, el discurso del contrato social, el discurso de la soberanía y por último el discurso de la razón de Estado (principalmente utilizado por "políticos" maquiavelianos y anti-maquiavelianos) $)^{34}$. A excepción de este último, los tres otros discursos recurrían a elementos de la teoría política aristotélica, y se servían de ellos en función de sus propias problemáticas. El discurso de la razón de Estado en cambio procede a un análisis político en el que se privilegian distintos aspectos según que el discurso sea maquiaveliano o anti-maquiaveliano; e incluso al interior del discurso anti-maquiaveliano, se pueden distinguir diversas corrientes ${ }^{35}$. Sin embargo, un punto en común reúne a estos discursos de la razón de Estado: la tela de fondo sobre la que se dibuja el actuar político es siempre la historia, y la historia privilegiada es la de Roma.

Ahora bien, estos discursos se organizaban en torno a un cierto número de exigencias que es necesario precisar. Estas exigencias constituyen el "campo de presencia" sobre el cual tanto Hobbes como Spinoza formularon sus modelos de explicación de la generación del Estado. Podemos distinguir al menos cuatro tipos de exigencia de distinto valor: $1 /$ el principio de la anterioridad de la ley natural con respecto a la ley positiva (sea civil o divina); 2 / la exigencia de la caracterización de la conducta natural del hombre mediante la ficción de un estado anterior a la ley (divina, revelada); 3/ el principio de la universalidad del derecho natural; 4/ la exigencia de la determinación de la legitimidad del poder político por el origen (historia, Dios o pacto). Hay que decir que estos principios no son propiamente hablando conceptos; son las formas conceptuales o a priori históricos que definirán el "campo de presencia" del discurso filosófico de la modernidad temprana en torno a la política. Es sobre este suelo epistémico que Hobbes (y poco después Spinoza) buscarán resolver la cuestión del origen de la sociedad civil desde el punto de vista de la ciencia nueva: se tratará para ambos autores de determinar la sola causa eficiente del poder político (imperium o Civitas).

Sin detenernos en una caracterización rigurosa del procedimiento exacto a través del cual Hobbes inventa, entre 1640 y 1642 , lo que puede ser llamado, siguiendo a Jean Terrel, el "dispositi- 
vo teórico" de la doctrina propiamente moderna del pacto social o contractualismo, hagamos breve mención de este procedimiento ${ }^{36}$. En efecto, es posible concebir el contractualismo de Hobbes como la articulación inédita de tres tradiciones doctrinales heterogéneas del pensamiento político que hasta entonces habían coexistido de forma más o menos independiente. Hacemos referencia a 1/ la doctrina jurídico-teológica del derecho natural, $2 /$ los diversos modelos del contrato (jurídico, teológico y político, es decir aristotélico) y $3 /$ la teoría bodiniana de la soberanía ${ }^{37}$. Al ser articuladas al interior de un mismo dispositivo teórico, cuya finalidad consiste en concebir la naturaleza y límites del poder soberano, cada una de estas tres tradiciones será integrada como un elemento especifico de dicho dispositivo, es decir, en tanto que momento particular articulado a los otros según la coherencia interna del sistema. Es de esta forma, de hecho, que cada elemento adquirirá una función (un rol y un sentido) que no tenían en la tradición de la que Hobbes los saca. Recordemos estas diferencias: primero, el derecho natural dejará de ser pensado en función de los fines morales del hombre (que define el sentido mismo de la comunidad política), sino únicamente a partir de la perspectiva de la conservación del individuo ${ }^{38}$. Segundo, la doctrina del pacto no será entre gobernantes y gobernados ni servirá para una limitación del poder legítimo de los primeros, sino que, muy por el contrario, entre individuos de una multitud a la exclusión de un tercero, y sirve jus- tamente para transferir un poder ilimitado a ese tercero. Tercero, la teoría de la soberanía será desvinculada de su marco "histórico-teológico", para articularse directamente con la doctrina del pacto. Hobbes se posiciona en el campo problemático de la filosofía política de comienzos del siglo XVII mediante la elaboración consciente de este dispositivo conceptual original que radicaliza la tendencia convencionalista del origen del Estado. Nuestro objetivo será describir cómo Spinoza radicaliza por su parte la tendencia naturalista a partir de una crítica al dispositivo teórico hobbesiano.

\section{La generación naturalista del Estado en Spinoza: del derecho natural a la potencia de la multitud}

Es necesario precisar de entrada que nos restringiremos aquí al estudio de la génesis del Estado en el Tratado político (= TP), dejando de lado tanto los capítulos 16 y 17 del Tratado teológico-político (= TTP) como el escolio 2 de la proposición 37 de la Ética IV (E) ${ }^{39}$. Las razones que se pueden aducir son múltiples. Digamos simplemente que el Tratado político responde a un grado de expresión conceptual más acabado, prueba de lo cual es el hecho que Spinoza no utiliza el concepto de pacto para dar cuenta de la unión de los hombres en una sociedad política ni de la constitución del poder político ${ }^{40}$. Abordar las génesis del Estado propuesta por Spinoza en el TTP o en la Etica, nos llevaría más a un estudio comparado que diera cuenta de la eventual evolución del pensamiento político de Spinoza, cosa que ya ha sido hecha ${ }^{41}$. Por el contrario, 
si queremos estudiar de manera acabada el problema de la génesis del Estado en el capítulo II del TP, tendremos que mostrar que la "reconstrucción" de un "momento de la génesis del Estado" a partir de la ficción de una mecánica de las pasiones no sólo es inútil, sino que impide la comprensión exacta del dispositivo teórico propio de Spinoza. En efecto, creemos que el Estado debe ser comprendido como una propiedad de la esencia del hombre, propiedad que tiene como característica de ser intrínseca a la naturaleza humana.

a) Spinoza frente al "aristotelismo político": la presencia de la historia

El párrafo 1 del primer capítulo del TP (=TP 1/1), contiene una breve pero radical crítica a la totalidad de las teorías políticas filosóficas expuestas hasta ahora (1675), puesto que todas se han fundado sobre una naturaleza humana que responde más a los deseos de aquellos teóricos (filósofos o teólogos) que han escrito sobre política que a la realidad ${ }^{42}$. El gran problema reside en que, contrariamente a los "políticos", los teóricos han construido sus sistemas sin tener en cuenta la experiencia, "dicho de otro modo la práctica"43. ¿Qué es esta "experiencia"? ¿Se trata acaso de la experiencia de los hombres dedicados a la política, es decir, de aquella que éstos han obtenido en el ejercicio (usus) de gobernar? Hemos podido mostrar en otra parte que esta experiencia no es sino la experiencia histórica, o más bien, la historia de las instituciones tal y como es analizada por hombres que se han dedicado a la política (Antonio Pérez, Maquiavelo o Saavedra-Fajardo son algunos de los "políticos" que Spinoza conoce o cita) ${ }^{44}$. Dicho de otra forma, si es verdad, como dice André Tosel, que Spinoza pretende hacer "la teoría de una práctica", el proyecto consistirá entonces en elaborar una teoría de la experiencia que la historia ha transmitido de la política.

Ahora bien, ¿en qué consiste esta experiencia histórica? De modo general, la experiencia histórica ha enseñado tres cosas: 1 / que "todos los hombres, sean bárbaros o civilizados, se unen en todas partes (ubique) por costumbres y forman un statum civilis" (TP 1/7); 2/ "todos los géneros de Estado (Civitas) que pueden ser concebidos para que los hombres vivan en la concordia" 45 y $3 /$ "simultáneamente, los medios por los cuales se debe dirigir a la multitud, o con los cuales se la debe contener al interior de ciertos límites" ${ }^{\$ 4}$. A esta experiencia propiamente política, habría que agregar la experiencia que el hombre político adquiere respecto de la conducta humana, la que de hecho será ampliamente descrita en TP 1/5. En lo que concierne a nuestro estudio, sólo es necesario mencionar la primera y más general de las enseñanzas de la experiencia, a saber que todos los hombres, es decir todos los grupos humanos "forman algún estado de civilidad". En efecto, por esta afirmación, Spinoza está sin duda haciendo mención de las diferentes "historias" de que disponía de la formación de algunos Estados, aquellas precisamente escritas por los autores que acabamos de mencionar: la formación del Estado romano por Maquiavelo y Tácito, la formación del Estado español por Saavedra-Fajardo y la formación del Estado aragonés por 
Antonio Pérez (habría que agregar, por cierto, la historia de la fundación del Estado mosaico).

Ahora bien, ¿es posible asimilar esta experiencia histórico-política a la "experiencia" que Aristóteles trae a colación al comenzar su Política? Dicho de otra forma, ¿es posible incluir esta tradición en la episteme del aristotelismo político? Sin embargo, la experiencia histórica de la fundación de un Estado puede servir para corregir la experiencia histórica propuesta por Aristóteles al comienzo de su Política. $\mathrm{Y}$ es que todas estas historias comienzan, no por familias, sino por grupos o, si se prefiere, multitudes que tienden a organizarse por la ocupación y defensa de un territorio. De hecho, las "familias" es una institución determinada políticamente en el marco de una cierta forma de Estado (más precisamente, del Estado monárquico, TP 6/11) y suponen por lo mismo la elección de una cierta forma de organización política y no al revés. No queremos decir con esto que, desde un punto de vista histórico, no se pueda asignar un cierto origen a la formación de un Estado particular. Pero ciertamente, ese origen no residirá en la familia, sino en una "multitud originaria". Lo que no quiere tampoco decir que esas multitudes originarias no tengan sus propias historias, y sean ellas mismas el resultado de otras historias. Pero, como la serie de las causas es infinita, la historia debe suponer un origen de modo más o menos arbitrario y explicar desde ahí el surgimiento de un estado particular. Una vez corregida o racionalizada la experiencia histórica, ¿cómo procederá la explicación racional de este hecho histórico?
La crítica de Spinoza al aristotelismo político no es, como en Hobbes, la de una suerte de falta de radicalidad a la hora de pensar el artificio por el cual el Estado (i.e. la voluntad del soberano) es creado. La crítica radicará más bien en la articulación entre estas dos series, presentadas en el libro primero de la Política de Aristóteles, que son el hecho (la experiencia de la formación histórica de la Polis) y el derecho (la explicación de ese hecho por la causa final). Tanto para Hobbes como para Spinoza, una ciencia política debe determinar la causa eficiente de la generación del Estado. Hobbes romperá la serie familiaaldea-ciudad-Polis, momento este último de la convención entre hombres libres, eliminando la idea de "animal político", para situar la causa en el pacto de unión-sumisión de las voluntades ${ }^{47}$. Por el contrario, Spinoza concebirá la serie factual como multitudes "en proceso de": ya sea en proceso de politización (de convergencia y unión) ya sea de despolitización (de divergencia y disolución). Serie cuya explicación racional procederá primero a una eliminación de la mediación convencionalista, para situar la causa en el "animal social", concepto que expresa no ya una aptitud para la vida en sociedad, sino que una condición de existencia de la potencia que lo define individualmente (TP 2/15). No hay individuos fuera de la multitud. De ahí la radicalidad del naturalismo de Spinoza que no requiere de la mediación de las leyes para concebir la formación del Estado, ni de un salto cualitativo que nos haga pasar al "estado político" (presente tanto en Aristóteles como en Hobbes). Veamos todo esto más en detalle. 
b) Estado de naturaleza y estado de civilidad: análisis de la cosa política

La construcción de la definición genética del Estado en el Tratado político está inserta en una argumentación más vasta, que pasa por dos puntos esenciales. En un primer momento, Spinoza determina el contenido de la noción de "derecho" por una identificación del derecho natural de Dios sobre todas las cosas y de su potencia infinita de actuar ${ }^{48}$. De esta forma, Spinoza deducirá que cada cosa natural "tiene tanto derecho como vale por su potencia" "49. En un segundo momento, Spinoza hará una pregunta que parece desviarse de la búsqueda de las "causas y fundamentos naturales del Estado" 50 , a saber: ¿cómo concebir el derecho natural propio del género humano? Sin embargo, será fundamental para la concepción naturalista propia de Spinoza, puesto que le permitirá situar la causa eficiente del Estado en la multitud (más bien que en el individuo).

El primer punto que debemos abordar es la relación que establece Spinoza entre derecho natural y leyes de la naturaleza. Puesto que este punto ha sido ya muchas veces señalado por la crítica, sólo indicaremos los puntos esenciales ${ }^{51}$. Como dijimos, el Tratado político comienza identificando el derecho de Dios sobre todas las cosas a su omnipotencia creadora. Con respecto a esta identificación, hay que decir que constituirá el fundamento de toda la deducción de la causa del Estado. Pero, lo que será completamente escandaloso para la época es lo que Spinoza deducirá de esta primera identificación: la potencia de cada cosa natural, es decir "creada" $"$, por la que existe y persevera en su existencia, es la potencia misma de Dios. El contenido del derecho natural en su expresión más alta, es decir, en Dios, no es sino potencia. Spinoza procederá estableciendo una equivalencia entre la potencia de la totalidad de las cosas singulares y la potencia eterna e infinita de Dios. De modo tal que la potencia de cada cosa singular será una parte de la potencia infinita de Dios. En la medida en que las cosas naturales implican a Dios como su principio causal, ellas no podrán ni existir ni obrar sin Dios ${ }^{53}$. Es esta relación de inmanencia o implicancia la que permite la identificación, en principio, de la potencia de cada cosa natural a la potencia de Dios ${ }^{54}$.

Se plantea así una pregunta: ¿cómo será determinado este contenido del derecho natural? Es decir: ¿cómo debemos concebir esta "potencia" de cada cosa? Es aquí donde tendrá lugar una tercera identificación: el derecho natural de cada cosa natural será identificado a las "leyes naturales" por las que es determinado a existir y actuar. En efecto, si el derecho natural de Dios es identificado a la potencia de la Naturaleza por la cual todas las cosas son determinadas a existir y a obrar, entonces el derecho natural de Dios no es otra cosa sino "las leyes o reglas mismas de la naturaleza según las cuales todas las cosas llegan a ser" ${ }^{55}$. Y como la potencia que define cada cosa es una parte de la potencia de Dios, el derecho natural de cada cosa será identificado con las leyes de su propia naturaleza. Es por esta razón que Spinoza podrá decir que "todo lo que cada hombre hace 
(agit) según las leyes de su naturaleza, lo hace (agit) por el supremo derecho de la naturaleza, y tiene sobre la naturaleza tanto derecho como vale por su potencia" ${ }^{56}$. Así, los diferentes tipos de conductas a los que la razón o la pasión nos "conducen", en la medida en que son efectos que se explican por un cierto tipo de determinación (ya sea racional, ya sea pasional) del conatus del hombre, se ven plenamente legitimados por el derecho natural ${ }^{57}$. Dicho de otro modo, si por legítimo entendemos lo que es hecho por derecho, Spinoza demuestra que, según el derecho natural, todo hecho es legítimo y así también lo es toda conducta ${ }^{58}$.

El segundo punto concierne los conceptos de estado de naturaleza (statum naturalis) y estado de civilidad (statum civilis) desde el punto de vista lógico. ¿Cuál es la función lógica del concepto de estado de naturaleza en la deducción del fundamento del Estado? Pareciera que el concepto spinociano de "estado de naturaleza" conlleva cierta equivocidad. Para Hobbes, recordémoslo, este concepto viene a desplegar las consecuencias de los movimientos "libres" del individuo en el seno de una multitud, determinando las relaciones interhumanas independientemente de aquellas instituciones que lo obligan a una conducta "civil". Pero para ello, es necesario suponer una dinámica propia a dicho estado que permanentemente lo lleve al límite ficticio de una guerra de cada cual contra cada cual. Este límite, Hobbes lo concibe como el verdadero estado de naturaleza o "estado de pura naturaleza", cuya diferencia para con los "estados de naturaleza" históricamente localizados, es determinado como condición de imposibilidad de la vida humana. A este respecto, es de notar que Spinoza no hablará nunca de un "estado de pura naturaleza". Muy por el contrario, Spinoza usará el concepto de estado de naturaleza para describir algo muy concreto, a saber, "la condición común del hombre" o, dicho de otra forma, el hecho de vivir conducidos por las pasiones más que por la razón. Es por ello que en TP 2/8, Spinoza afirma que los hombres pasan la mayor parte de su vida en dicho estado, así como una "continuación" del estado de naturaleza en el estado de civilidad ${ }^{59}$. Sin embargo, también es cierto que, en el decisivo párrafo 15 del capítulo II del TP, Spinoza se valdrá de este concepto como de una condición de imposibilidad, dándole un sentido similar al que le daba Hobbes: un sentido hipotético. ¿Cuál es esta hipótesis? Resumámosla: si considerásemos a los hombres conducidos a actuar de tal modo que fuesen determinados únicamente por sus pasiones, entonces no habría género humano ${ }^{60}$. En palabras de Spinoza, el derecho natural sería "más una opinión que una cosa" ${ }^{1}$.

Ahora bien, surge la pregunta acerca de la unidad del concepto de estado de naturaleza. Por una parte en efecto, dijimos que expresaba lo más concreto de la condición del hombre, y por la otra, la mera imposibilidad de su existencia. ¿Existe entonces una unidad del concepto de estado de naturaleza en Spinoza? Nos parece que sí. En efecto, creemos que dicha hipótesis será formulada simplemente a partir de una determinación exclusiva 
de las relaciones entre los hombres por las pasiones. Desde este punto de vista, los hombres son, nos dirá Spinoza, enemigos los unos de los otros ${ }^{62}$. Ahora bien, la existencia del género humano, así como la de los individuos que lo componen, es un hecho del cual no sólo la razón pura sino también las pasiones solas (es decir, el estado de naturaleza) son incapaces de dar cuenta. Así, si la causa de este hecho no puede ser hallada ni en cada hombre determinado únicamente por sus pasiones ni en la pura razón, ésta deberá ser buscada no sólo en la "vida en común”, esto es en la sociedad, sino más precisamente en el establecimiento de "reglas comunes" capaces de determinar las relaciones entre los hombres, es decir, en una sociedad política. Leamos la respuesta dada por Spinoza en TP 2/15: "el derecho natural propio al género humano" sólo puede ser "concebido ahí donde los hombres tienen reglas de derecho comunes según las cuales pueden al mismo tiempo $1 /$ reivindicar tierras habitables y cultivables, $2 /$ protegerse y rechazar toda fuerza y 3 / vivir según el sentir común de todos". Estas tres condiciones de la existencia del individuo caracterizan el "estado de civilidad"63.

En su forma abstracta entonces el estado de naturaleza representa la condición de imposibilidad lógica de concebir el derecho natural individual como una fuerza de existir efectiva, capaz justamente de hacer que el "esfuerzo por perseverar en su ser" produzca los efectos necesarios para esta perseverancia. De la imposibilidad de concebir la existencia del derecho natural del hombre a partir de la abstracción del estado de naturaleza, es decir, a partir de la naturaleza del hombre determinada exclusivamente por las pasiones, se deduce la necesidad de una determinación social del hombre. De modo tal que el estado de civilidad o Estado, estará con respecto a la naturaleza humana en la relación descrita por Spinoza en la definición 6 de la Ética II, a saber: "Digo que pertenece a la esencia de una cosa aquello que, siendo dado, pone necesariamente la cosa, y que, siendo suprimido, elimina necesariamente la cosa; o, aquello sin lo cual la cosa e inversamente, aquello que sin la cosa no puede ni ser ni concebirse". El estado de civilidad es una propiedad de la naturaleza humana; no se trata de decir, por supuesto, que el Estado, como forma de organización política específica, esté implicado en el conatus de cada hombre singular. Pero el que sea una propiedad de la naturaleza humana requerida para concebir la existencia del género humano, explica que cada hombre en particular tenga un "apetito natural de vivir en un estado de civilidad" (statum civilem homines natura appetere, TP 6/1).

Creemos que esta demostración es autosuficiente en la medida justamente en que es puramente formal, es decir, que omite todo contenido empírico, toda determinación causal por una pasión particular. Y la omite, no con el fin de disimularla, sino porque no la requiere. Y la razón está en que estas tres condiciones conciernen la condición de posibilidad de la existencia de una potencia en particular, es decir una cuestión de derecho. Así, contrariamente a lo supuesto por Mathe- 
ron, no puede hablarse de una "ausencia", en el párrafo 15, del "momento de la génesis", ni de la necesidad de su "reconstrucción". De suerte que se explica la diferencia entre Hobbes y Spinoza en lo relativo al concepto de estado de naturaleza. Para Hobbes, es fundamental describir y definir el concepto mediante la ficción de hombres nacidos como hongos. Para Spinoza en cambio, basta llevar al límite una tendencia existente en la naturaleza humana: la tendencia a conducirse determinados exclusivamente por las pasiones.

Con ello podemos abordar el tercer $\mathrm{y}$ último punto, relativo a la relación del estado de naturaleza y del estado de civilidad desde el punto de vista ontológico. En efecto, queda aún por responder a la pregunta respecto del contenido de los conceptos de estado de naturaleza y de estado de civilidad. Nuestra hipótesis de lectura es que estado de naturaleza y estado de civilidad son conceptos que sirven para describir una sola y misma realidad determinada por tendencias distintas, de manera que para encontrar el contenido real de estos conceptos es necesario pensarlos como recíprocamente implicados. Esto quiere decir que son correlativos y expresan situaciones simultáneos. Ahora, ¿por qué hablar más bien de estado de naturaleza que de civilidad o la inversa? Esto es posible puesto que la realidad que estos conceptos describen puede tender hacia uno u otro de estos estados, según las proporciones en que se encuentran "mezclados". De modo que el estado de naturaleza no es el origen ni ficticio ni real de la sociedad civil -el origen tanto del estado de civilidad como del estado de naturaleza en sus existencias concretas, es decir simultáneas, no es sino el conatus individual concebido como parte de una multitud-. Del estado de naturaleza debemos decir que ha existido siempre (entiéndase: tiene la edad que tiene el hombre) y que es inexistente, pero en grados diversos. En tanto que estado abstracto o puro, no ha existido nunca puesto que es la condición de imposibilidad de la existencia del hombre. Pero en tanto que expresión del derecho natural, del mismo modo que el Estado no puede nunca ser completamente disuelto ${ }^{64}$, el estado de naturaleza "continúa" en el estado de civilidad ${ }^{65}$. La hipótesis de una determinación del hombre que fuera únicamente por sus pasiones, constituiría el "grado cero" del estado de naturaleza, que representa el límite de la posibilidad de la existencia del hombre, o la condición absoluta de su imposibilidad. Así, el concepto de "estado de naturaleza" debe ser considerado como una tendencia cuyo límite está en la negación de las condiciones de la existencia de la esencia actual del hombre, es decir de su conatus ${ }^{66}$. Y hemos de decir lo mismo del estado de civilidad, y de las tres "formas" que éste puede adoptar, a saber: la Monarquía, la Aristocracia y la Democracia. Cada una de estas formas son modalidades que expresan un cierto grado de estado de civilidad $^{67}$. De suerte que si, como dijimos, estado de civilidad y estado de naturaleza son simultáneos, entonces, no sólo éste último sino que ambos expresarán tendencias a la vez opuestas e implicadas entre $s i^{68}$. 
Queda un punto por esclarecer: ¿cómo interpretar en efecto las múltiples ocasiones en que Spinoza habla de un "retorno al estado de naturaleza" 69 ? En efecto, la idea de una "vuelta" pareciera sugerir que en algún momento hubo una "salida". Sin embargo, la idea de un "regreso" al estado de naturaleza expresa simplemente el hecho de que los procesos de descomposición del imperium asociados a la tendencia anti-política propia del estado natural tiene la primacía por sobre la tendencia a la composición política asociada al concepto de estado de civilidad. Al respecto, no es inútil recordar la "principal diferencia" que Spinoza hacía entre estos dos estados: ésta consiste en "que en el estado de civilidad todos tienen los mismos miedos, y que la seguridad tiene para todos la misma causa, y que la regla de vida es común" "70. El contenido de estos dos estados es fundamentalmente el mismo: afectos (de miedo y de seguridad), es decir fuerzas, y reglas de vida, es decir determinaciones pasionales y racionales diversas de la conducta. La diferencia radica en aquello que estaría al origen de dichos afectos y reglas de vida en cada uno de estos estados: 1/ el imperium como poder común en el estado de civilidad y 2 / cada cual según su juicio y sus fuerzas en el estado de naturaleza.

De esta forma podemos pasar al punto que consideramos más importante de nuestra hipótesis. En efecto, dijimos que el estado de civilidad, tal y como es definido por sus propiedades en el párrafo 15 , constituía a su vez una denominación intrínseca de la naturaleza humana. Sin embargo, Spinoza irá más lejos: nos dará una definición genética del imperium a partir de la cual será posible comprender lo que constituye la esencia de esta "propiedad". Citemos a Spinoza: "Ese derecho, que se define por la potencia de la multitud, suele ser llamado imperium". Es menester ahora detenerse un momento en este punto. El imperium es el nombre, nos dirá Spinoza, que suele ser dado a cierto derecho. Este derecho, como todo derecho, es idéntico a una potencia, la que corresponde no a los hombres considerados independientemente los unos de los otros, sino que a la multitud organizada. Así, nos lo recuerda Matheron, el derecho civil es, por lo tanto, nada más que el derecho natural de una multitud que se define por su potencia. Pero eso no es todo. Estas consideraciones nos permiten entender además la relación entre potencia de la multitud, estado de naturaleza y estado de civilidad. Creemos que la potencia de la multitud debe ser considerada como la instancia que constituye la unidad de estas dos tendencias ${ }^{71}$. Es más, que estas dos tendencias son las dos variaciones constituyentes de los dos modos a través de los cuales la potencia de la multitud puede ser afectada. Así cuanta más fuerza posean las causas externas, sea por la "mala suerte" de la Fortuna, sea por una mala organización de las instituciones políticas, mayor será la tendencia de la potencia de la multitud a disgregarse en potencias particulares ${ }^{72}$. La potencia de la multitud tiende entonces al estado de naturaleza como modo de afección principal. Por el contrario, cuanta más fuerza reúna la colectividad, por medio de algún afecto común, mayor será 
la tendencia de la potencia de la multitud a hacerse común. Y mientras más fuerte sea esta tendencia, mayor será también la potencia de cada hombre. Así, la potencia de la multitud tenderá hacia un cierto grado de estado de civilidad, el cual determinará la forma de Estado adoptada por la multitud. Y es así también como podemos entender en su principio estas "idas y venidas" de un estado al otro: en la medida en que estas tendencias dependen de una sola potencia, lo que está en juego es justamente sus relaciones de fuerza ${ }^{73}$, así como las condiciones de reversibilidad de la una a la otra.

\section{Conclusión}

Esperamos haber mostrado que, contrariamente a una historiografía común, el contractualismo moderno de Hobbes no se opone a un pseudo-naturalismo supuestamente omnipresente desde Aristóteles hasta la escolástica tardía, consumando así la ruptura entre discursos pre-modernos y la modernidad en filosofía política. Las cosas son algo más complejas. Primero, porque el dispositivo teórico del contractualismo hobbesiano se sitúa en el horizonte de un "aristotelismo político" que contenía tanto discursos convencionalistas como naturalistas. Segundo, porque entonces un teórico de la política como Spinoza o bien, si se considera como un naturalista, simplemente quedaría fuera de la "modernidad" de la filosofía política, o bien, cuando se le considera como un contractualista (como es el caso la mayor de las veces en los manuales de filosofía política), se pierde de vista la originalidad de del dispositivo teórico que elaboró para dar cuenta de la génesis del Estado.

Hobbes y Spinoza se sitúan ambos frente a mismo un campo problemático. Spinoza no es un mero lector de Hobbes; Hobbes no rompió la historia de la filosofía política en dos. Ciertamente la invención hobbesiana del contractualismo es de extrema importancia, pero el campo de presencia sobre el que intervino Hobbes aún opera. Hobbes reveló o produjo una falla, pero aún era demasiado temprano como para que pensadores como Spinoza e incluso Locke no pudieran situarse a la vez frente a Hobbes, sobre el campo horadado por éste último, y frente a otras tradiciones, según otras perspectivas. Hobbes ve una falla en el aristotelismo político que no atina a construir ni una verdadera antropología ni un verdadero contractualismo: ni completamente naturalista ni completamente contractualista, el aristotelismo político radica en una suerte de compromiso entre ambas corrientes. Así, el dispositivo teórico hobbesiano llevará al contractualismo hacia un artificialismo radical. Por el contrario, Spinoza situará el problema del aristotelismo político en la relación entre teoría y práctica, lo que de hecho le permitirá incluir al propio Hobbes. Spinoza elaborará un dispositivo teórico capaz de dar cuenta de la experiencia histórica racionalmente elaborada por los discursos de la razón de Estado. Así, sobre el espacio abstracto (o imaginario) de la praxis histórica articulará los discursos del derecho natural y de la soberanía para dar cuenta del imperium mediante el concepto complejo de potentia multitudinis. 


\section{BIBLIOGRAFÍA}

Aristote, 2015, Les politiques. Traduction de P. Pellegrin. Paris, GF Flammarion.

Aristóteles, 1988, Politica. Introducción, traducción y notas de M. García Valdés. Madrid, Gredos.

Balibar E., 2001, "Potentia multitudinis, quae una veluti mente ducitur". En Senn M. y Walther M. (eds.), Ethik, Recht und Politik bei Spinoza. Zurich, Schulthess, p. 105-133.

Bertelloni F., 2011, "Natura multipliciter dicitur. Variantes en el uso del concepto de natura en la teoría política medieval a partir de la segunda mitad del siglo XIII". Scripta Vol. 4, No 2, p. 11-30.

Bodin J., (1583) 1977, Les six livres de la République. Aleen, Scientia Verlaag.

Brett A., 2002, "Natural Right and Civil Comunnity:The Civil Philosophy of Hugo Grotius", The Historical Journal, Vol. 5, $\mathrm{N}^{\mathrm{o}} 1$, pp. 31-51.

Chaui M., 2004, Politica en Spinoza. Buenos Aires, Gorla.

Courtine J.-F., 1999, Nature et empire de la loi. Paris, Vrin-EHESS.

Den Uyl D. Jr., 1983, Power, State and Freedom. An Interpretation of Spinoza's Political Philosophy. Assen, Van Gorcum.

Flash K., 2010, Introduction à la philosophie médiévale. Paris / Fribourg, Cerf / Academic Press Fribourg.

Foucault M., 1969, Archéologie $d u$ savoir. Paris, Gallimard.

Grocio H., (1625) ${ }^{1} 1867,1999$, Le droit de la guerre et de la paix. Traduction Pradier-Fodéré. Paris, PUF.

Hobbes Th. (1647), 1839, Opera Philosophica quae Latine scripsit. Studio et labore Gulielmi Molesworth, Vol. II. Londini, apud Joannem Bohn.

Hobbes Th, (1647) ${ }^{1} 1983,1987$, De Cive. The English Version entitle in the First Edition Philosophicall Rudi- ments Concerning Government and Society. A critical Edition by Howard Warrender. Oxford, Clarendon.

Hobbes T., (1647) 2000, Tratado del ciudadano. Traducción, prólogo y notas de Carlos Mellizo. Madrid, Alianza.

Hobbes Th., (1647) 2010, Du citoyen. Présentation, traduction et notes par Philippe Crignon. Paris, GF Flammarion.

Joucla-Ruau A., 1977, Le tacitisme de Saavedra-Fajardo. Paris, Editions Hispaniques.

Lazzeri Ch., 1998, Droit, pouvoir et liberté. Spinoza critique de Hobbes. Paris, PUF.

Maravall J. A., 1997, La teoría del Estado en España en el siglo XVII. Madrid, Centro de Estudios Constitucionales.

Matheron A., 1969, Individu et communauté chez Spinoza. Paris, Minuit.

Matheron A., 2011, Etudes sur Spinoza et les philosophies de l'âge classique. Lyon, ENS Editions.

Michaud-Quantin P., 1970, Universitas. Expressions du mouvement communautaire dans le Moyen-Age latin. $\mathrm{Pa}-$ ris, Vrin.

Moreau P.-F., 1995, Spinoza. Expérience et éternité. Paris, PUF.

Rosler A., 2002, "Hobbes y el naturalismo político en Aristóteles". Deus Mortalis, 1, p. 27-54.

Terrel J., 2001, Les théories du pacte social. Droit naturel, souveraineté et contrat de Bodin à Rousseau. Paris, Seuil.

Tosel A., 1994, Du matérialisme de Spinoza. Paris, Kimé.

Senellart M., 1989, Machiavélisme et raison d'Etat XII ${ }^{e}-X V I I I^{e}$ siècles. $\mathrm{Pa}-$ ris, PUF.

Skinner Q. 2003, El nacimiento del Estado. Traducción de Mariana Gainza. Buenos Aires, Gorla.

Spinoza B., (1677) 2005, Euvres $V$. Tractatus politicus / Traité politique. Edition publié sous la direction de P.- 
F. Moreau. Texte établi par Omero Proietti. Traduction, introduction, notes, glossaires, index et bibliographie par Charles Ramond. Paris, PUF. Spinoza B., (1677) 2009, Ética. Edición y traducción de Atilano Domínguez. Madrid, Trotta.

Suárez F., (1612) 1967-1968, Tratado de las leyes y de Dios legislador. Edición bilingüe en seis volúmenes. Madrid, Instituto de Estudios Políticos.
Vitoria F., (1528) 2008, Relectio de potestate civili. Madrid, Consejo Superior de Investigaciones Científicas.

Thomas Aquinas, 1953, The Political Ideas of Thomas Aquinas. Representative Selection. Edited with an Introduction by Dino Bigongiari. NewYork, Hafner publishing company.

Tomás de Aquino, 2003, Del reino o gobierno de los príncipes. Buenos Aires, Losada.

\section{NOTAS}

${ }^{1}$ Este trabajo forma parte del proyecto FONDECYT N ${ }^{\circ} 3160088$

${ }^{2}$ La traducción de imperium por Estado no deja de ser problemática, puesto que se da como constituido un concepto que está en plena formación. En estricto rigor, el imperium designa, en Spinoza al menos, el poder político que da fuerza de ley a lo sancionado por el hombre o asamblea al que se le atribuye. Respecto de la formación de la noción de Estado, ver Q. Skinner, El nacimiento del Estado, Buenos Aires, Gorla, 2003. Cuando hablamos aquí de "generación del Estado", nos referimos tanto a la generación del cuerpo político (lo que Spinoza llama en el Tratado político, la Civitas) como al poder político (el imperium).

${ }^{3}$ Cf. Den Uyl D. Jr., Power, State and Freedom. An Interpretation of Spinoza's Political Philosophy. Assen, Van Gorcum, 1983 y Matheron A., Individu et communauté chez Spinoza, Paris, Minuit, 1969. A propósito del debate entre estos dos autores en torno a la concepción spinociana del Estado, ver Moreau P.-F., Spinoza. Expérience et éternité, Paris, PUF, 1995, p. 427-465. Ver también Balibar E., "Potentia multitudinis, quae una veluti mente ducitur", en Senn M. y Walther M. (eds.), Ethik, Recht und Politik bei Spino$z a$, Zurich, Schulthess, 2001, p. 112.

${ }^{4}$ Cf. Matheron, Op. Cit., p. 300 y ss. Más tarde, Matheron dirá que la génesis del Estado está efectivamente presente en el Tratado político, pero no en el lugar en el que debiera encontrarse (sc. TP 2/15). Mediante una serie de reenvíos operados por Spinoza, sería posible encontrar dicha génesis, disimulada en TP 3/9. La razón de esta disimulación radicaría, según Matheron, en las reticencias que Spinoza habría tenido al darse cuenta de que la pasión generadora del Estado era la indignación, pasión fundamentalmente mala (según Ética IV 51 Esc.), es decir la misma por la cual el Estado es destruido. Cf. "L'indignation et le conatus de l'Etat", en Etudes sur Spinoza et les philosophies de l'âge classique, Lyon, ENS Edition, 2011, p. 219 229.

Para el concepto de a priori histórico, ver Foucault M., L'archéologie du savoir, Paris, Gallimard, 1969 , p. 166-173; por a priori histórico, "entiendo designar un a priori que es, no la condición de validez de un juicio, sino una condición de realidad para los enunciados", p. 167. Más precisamente, el a priori histórico "se define como el conjunto de reglas que caracterizan una práctica discursiva", p. 168.

${ }^{6} \mathrm{Cf}$. Aristóteles, Política, I, 2, 1253a 3. Utilizamos la traducción al castellano de M. García Valdés (Madrid, Gredos, 1988) y al francés de P. Pellegrin (Paris, GF Flammarion, 2015). Si bien Hobbes, al usar el concepto de zoon politikòn hace una clara referencia a Aristóteles, también es cierto que al hacer de esta idea una concepción "griega", puede incluso estar pensando en Platón, para quien la unión de los hombres en comunidades se debe a la debilidad de su naturaleza. Un caso de articulación de la idea de la debilidad y de la sociabilidad natural se encuentra las Relecciones sobre el poder civil (1528) de Francisco Vitoria. Desde este punto de vista, acaso la denominación "idea griega", deba entenderse como una filiación genealógica, la que iría de Aristóteles al aristotelismo del siglo XVI, pasando por Cicerón, y la escolástica medieval.

${ }^{7}$ Contra esta lectura, historiadores de la filosofía política moderna como Jean Terrel en su libro importante sobre Les théories du pacte social. Droit natural, souveraineté et contrat de Bodin à Rousseau, Paris, Seuil, 2001, y medieval, como Francisco Bertelloni en sus numerosos trabajos (p. ej., "Natura multipliciter dicitur. Variantes en el uso del concepto de natura en la teoría política medieval a partir de la segunda mitad del siglo XIII", Scripta Vol. 4, No 2, 2011, p. 11-30), han insistido en que ni el "aristotelismo político medieval" es tan aristotélico como se presupone ni el naturalismo aristotélico exclusivamente aristotélico.

${ }^{8}$ De Cive 1/2. La traducción es nuestra. Utilizamos la edición latina de Molesworth: Thomae Hobbes Malmesburiensis Opera Philosophica quae Latine scripsit, studio et labore Gulielmi Molesworth, Vol. II, Londini, apud Joannem Bohn, 1839 y la inglesa editada por H. Warrender: Thomas Hobbes, De Cive. The English Version entitle in the First Edition Philosophicall Rudiments Concerning Government and Society. A critical Edition by Howard Warrender, Oxford, Clarendon, 11983 , 1987. Hemos teniendo presente las traduccio- 
nes realizadas por C. Mellizo (Madrid, Alianza, 2000) al castellano, M. Silverthorne (Cambridge University Press, 11998, 2003) al inglés y Ph. Crignon (Paris, GF Flammarion, 2010) al francés.

${ }^{9}$ Ibíd., Op. Cit.

${ }^{10}$ Ibíd.

${ }^{11}$ Como es sabido, esta obra se atribuye habitualmente a Anaxímenes de Lampsaco (a partir de la edición de M. Fuhrmann de 1966); pero según P. Chiron en su edición de la obra (2002), la atribución es sólo verosímil. Como sea que fuere, lo importante aquí es que lo que llamamos "aristotelismo político" de los siglos XVI y XVII se desprende de un corpus heterogéneo, que en ningún caso puede reducirse a la obra de Aristóteles.

${ }^{12}$ De Cive, $14 / 2$.

${ }^{13}$ Ibíd.

${ }^{14}$ Ibíd.

${ }^{15}$ Ibíd., 5/8; la generación del Estado es expuesta en De Cive V, en particular en los párrafos 6 a 11 .

16 Política, I, 2, 1252b 12-22. La Polis indica el pleno desarrollo histórico-natural de las colectividades humanas: los bárbaros, nos dirá Aristóteles, contrariamente a los griegos, aún no viven en Polis. - Así, contrariamente a algunas interpretaciones, si bien es cierto que, para Aristóteles, el individuo es cronológicamente anterior a la Polis, ello no significa 1/ que Aristóteles piense que la Polis es una formación creada por un conjunto de individuos, puesto que la primera unidad real, para Aristóteles, constitutiva de la Polis y capaz de vivir "fuera" de ella es la familia, no el individuo. 2/ Tampoco quiere esto decir que, una vez la Polis formada, el individuo pueda salirse de ella a voluntad. De hecho, se vuelve dependiente de ella en orden a perfeccionar su naturaleza y es únicamente por azar o porque se trata de una bestia o de un dios que un individuo puede vivir fuera de la Polis. (Cf. Rosler A., "Hobbes y el naturalismo político en Aristóteles", Deus Mortalis, 1, 2002, p. 27-54, en particular p. 34.)

${ }^{17}$ Op. Cit., ibíd., $1252 \mathrm{~b} 32$.

${ }^{18}$ Op. Cit., ibíd., 1252a 25 (traducción ligeramente modificada a partir de la traducción francesa de Pellegrin).

${ }_{19} O p$. Cit., 1253a 20. Es difícil saber si es el ser humano el que es definido como "animal político" o sólo el hombre adulto y libre, es decir el ciudadano.

${ }^{20} \mathrm{Sin}$ embargo, los intelectuales que adoptaron las tesis del aristotelismo político identificaron la politicidad natural del hombre a la insuficiencia de su naturaleza a conservarse, haciendo de ésta la causa final de la unión de los hombres en un cuerpo político. Es el caso de Francisco Vitoria quien, después reconocer la incapacidad de la naturaleza humana para conservarse, nos dice que "a partir de esta realidad, Aristóteles dice que el hombre es un animal social", Op. Cit., § 4. Pero era ya el caso de Tomás de Aquino, quien escribe en su Del reino o gobierno de los príncipes que "corresponde al hombre que sea un animal social y político, que vive en una multitud más aún que el resto de los animales, lo que por cierto su necesidad natural nos revela. En efecto, a los otros animales la naturaleza les deparó la comida, sus pieles, su defensa (...). El hombre en cambio está desprovisto de estos recursos dados por la naturaleza (...) Para obtener todas esas cosas un solo hombre no basta, pues un solo hombre por sí no podría pasar su vida con suficiencia. En consecuencia, es natural al hombre vivir en sociedad de muchos" (Buenos Aires, Losada, 2003).

${ }^{21}$ Op. Cit., 1253a 24-39. El texto en cuestión se encuentra en 1253a 29-32: "En todos existe por naturaleza la tendencia hacia tal comunidad, pero el primero que la estableció fue causante de los mayores beneficios" (el subrayado es nuestro). Es Terrel, $O p$. Cit., quien señala esta ambigüedad.

${ }^{22}$ Ver Terrel, Op. Cit., pp. 58-69.

${ }^{23}$ Para un estudio de esta obra, ver Terrel, Op. Cit., cap. 2.

${ }^{24}$ De jure belli ac paci, II, 5, § 7-8. Ver Terrel, Op. Cit., cap. 3.

${ }^{25}$ De legibus III, cap. 3 , § 6: "Y lo mismo que la libertad se la ha dado a cada uno el autor de la naturaleza, pero no sin la intervención de una causa próxima, o sea, del padre que lo produce, así este poder se lo da a la comunidad humana el autor de la naturaleza, pero no sin la intervención de las voluntades y del consentimiento de los hombres en virtud de los cuales tal comunidad perfecta se ha reunido". Ver J.-F. Courtine, Nature et empire de la loi, Paris, Vrin-EHESS, 1999 , cap. 2 y 5 .

${ }^{26}$ Vitoria F., Relectio de potestate civili, Madrid, Consejo Superior de Investigaciones Científicas, 2008, $\S 5$, p. 21: "Es evidente que la fuente y origen de las ciudades y de las repúblicas no está en una mera convención o en un invento humano, ni es algo que pueda incluirse entre las cosas artificiales, sino que debe considerarse como un avance que proviene de la naturaleza [tanquam a natura profectum], la que sugirió a los mortales esta forma [hanc rationem] para su defensa y conservación". Traducción ligeramente modificada.

${ }^{27}$ Jean Bodin, Les six livres de la République, Aleen, Scientia Verlaag, 1977, IV, cap. 1, p. 503: "Toda República tiene su origen en la familia, que se multiplica poco a poco. O bien se establece de golpe a partir de una multitud congregada o de una colonia sacada de otra República: como un nuevo enjambre o como una rama tomada de un árbol para plantarla, la cual, una vez que tiene raíces, da frutos más rápidamente que el que nace de una semilla". (La traducción es nuestra.)

${ }^{28}$ Cf. Michaud-Quantin P., Universitas. Expressions du mouvement communautaire dans le MoyenAge latin, Paris, Vrin, 1970.

${ }^{29}$ Para los distintos modelos de contrato presentes durante la Edad Media y hasta principios del siglo XVII, ver Terrel, Op. Cit., p. 59-60.

${ }^{30} \mathrm{El}$ naturalismo político es heredero de un naturalismo "contaminado" por los pensadores del Medio 
Evo. Como dice Bertelloni, art. cit., p. 18 : "los tratados políticos que intentaron explicar el nacimiento del «Estado» -concepto anacrónico en el medioevo- como surgido de la naturaleza, ni utilizaron la expresión $n a$ tura unívocamente ni siempre respetaron el significado que le atribuyó Aristóteles, sino que la expresión natu$r a$ fue muchas veces resemantizada para asumir en cada tratado un significado que solía combinar distintas tradiciones naturalistas y que, por ello, debe ser considerado como tributario o bien de las corrientes que desde el mundo clásico llegaron hasta el siglo XIII o bien de algún naturalismo producido por este mismo siglo, como podrían ser algunas variantes del naturalismo averroísta". Para el naturalismo político de Tomás de Aquino, ver p. ej. Flash K., Introduction à la philosophie médiévale, Paris / Fribourg, Cerf / Academic Press Fribourg, 2010, p. 179-186 y la introducción de Bigongiari a The Political Ideas of Thomas Aquinas. En lo referente a Vitoria, ver Terrel, Op. Cit., p. 67.

${ }^{31}$ Terrel, Op. Cit., ibíd.

${ }^{32}$ Vitoria, Op. Cit., $\$ 6$.

${ }^{33}$ Así, Vitoria podrá hablar de la situación de los hombres "antes de agruparse en sociedad", Op. Cit., § 7. Por otra parte, a pesar de que Vitoria asimila la causa eficiente del poder civil es la misma que la de la república, sc. Dios, y por lo tanto que es de Dios de quien procede el poder del rey (y no de la república), no es menos cierto que, al menos cuando se trata de una monarquía, es la república la que instituye al rey por una transferencia de la autoridad que ésta tenía sobre el poder civil que Dios le había otorgado, ver Op. Cit., $\S 8$.

${ }^{34}$ Las tres primeras fueron claramente distinguidas por Terrel, Op. Cit., sobre todo cap. 1. Para la relación entre Maquiavelo y la doctrina de la razón de Estado en su versión "proto-mercantilista", ver el libro importante de Senellart M., Machiavélisme et raison d'Etat XIIeXVIIIe siècles. Paris, PUF, 1989, sobre todo cap. 3.

${ }^{35}$ El discurso de la razón de Estado es un discurso "de historia política" (fundamento del "tacitismo", i.e. fundamento histórico, para los autores del barroco tanto español como italiano, de las máximas que deben guiar el actuar político), ver Maravall J. A., La teoría del Estado en España en el siglo XVII, Madrid, Centro de Estudios Constitucionales, 1997, cap. 2; ver también, Joucla-Ruau A., Le tacitisme de Saavedra-Fajardo, Paris, Editions Hispaniques, 1977, 22-24. Tácito es sin duda el autor de referencia para los autores "anti-maquiavelianos" de la razón de Estado que buscaban evitar el uso de Tito Livio (fuente de Maquiavelo en sus Discursos). Sin embargo, habría que distinguir, al interior del discurso anti-maquiaveliano de la razón de Estado, entre los "proto-mercantilistas" (como G. Botero) y los "consejeros" (como Saavedra Fajardo).

${ }^{36}$ Para más detalles, ver Terrel, Op. Cit., sobre todo cap. 1 y 4 .

${ }^{37}$ Terrel, Op. Cit., cap. 4.

${ }^{38}$ Terrel, Op. Cit., p. 106.
39 Para una comparación de las tres génesis del Estado, cf. Matheron, Op. Cit., (1969), p. 307-330. En lo referente a las obras de Spinoza, utilizamos en lo posible la nueva edición de PUF; para el resto, la edición de Gebhardt. Todas las traducciones de Spinoza son nuestras.

${ }^{40}$ Pero no solamente... En efecto, ha podido ser demostrado que la teoría de los afectos que se encuentra en la base de la teoría política no había sido completamente elaborada en el TTP, brillando por su ausencia el concepto fundamental de imitación afectiva; cf. los textos fundamentales de Matheron, "Le problème de l'évolution de Spinoza du Traité théologicopolitique au Traité politique", Op. Cit., (2011), p. 205218 y Lazzeri Ch., Droit, pouvoir et liberté. Spinoza critique de Hobbes, Paris, PUF, 1998, p. 284-287.

${ }^{41}$ Ver los textos citados en la nota anterior.

${ }^{42}$ Ver el artículo clásico de Matheron, "Spinoza et la décomposition de la politique thomiste: machiavélisme et utopie", Op. Cit. (2011), p. 81-111; ver también la discusión de Tosel A., "La théorie de la pratique et la fonction de l'opinion publique dans la philosophie politique de Spinoza", retomado en $D u$ matérialisme de Spinoza, Paris, Kimé, 1994, p. 105124.

43 TP $1 / 3$

${ }^{44}$ La historia está lejos de presentarse como un "dato" pasivamente descrito por los autores del siglo XVI que hacen uso de ella. Por el contrario, como toda verdadera experiencia, la historia debe ser construida de modo tal que pueda expresar lo que la razón demuestra.

${ }^{45} \mathrm{TP} 1 / 3$

${ }^{46}$ Ídem.

${ }^{47}$ Ver De Cive 5/7.

${ }^{48}$ Ver TP $2 / 2$ y 3.

${ }^{49} \mathrm{TP} 2 / 3$.

${ }^{50} \mathrm{TP} 1 / 7$

${ }^{51}$ Cf. Chaui M., Política en Spinoza, Buenos Aires, Gorla, 2004, p. 307-333. - Matheron lo ha señalado en numerosos artículos además de en su ya citada obra, por ej. en Op. Cit. (1969), p. 290-300.

${ }^{52}$ Spinoza hace aquí referencia a una distinción que ya había operado en el TRE entre cosas creadas e increadas, como se infiere del uso que hará más abajo del término en cuestión. Una cosa natural es una cosa creada y no una cosa finita, puesto que comprende en su concepto a los modos infinitos.

${ }_{53} \mathrm{El}$ argumento es el siguiente: como el concepto de una cosa natural no implica la determinación de su existencia o inexistencia, el principio de su existencia debe estar en otra cosa ("in alio", dirá Spinoza en la Ética). Dicho principio es la potencia misma por la cual esa cosa existe y persevera en su ser. Ahora bien, como toda cosa creada estará en este mismo caso, sólo podremos hacer depender la potencia de una "cosa natural" de la potencia divina. Así, la potencia de una cosa natural singular será identificada, en su principio, a la potencia de Dios, esto es a Dios mismo. 
${ }^{54}$ Pero sólo en principio. En efecto, la potencia de actuar de cada cosa (esto es: aquello que define su esencia) es una parte de la potencia eterna de Dios. Así, cada cosa es, siguiendo la fórmula de Charles Appuhn, un Deus quatenus.

${ }_{55}^{5}$ TP 2/4. Nótese que con ello Spinoza respeta el principio de la anterioridad de la ley natural respecto de la ley instituida.

${ }_{56} \mathrm{TP} 2 / 4$.

${ }^{57}$ TP 2/5: "y por consiguiente, la potencia natural de los hombres, o su derecho, deben ser definidos no por la razón, sino por todo apetito por el cual se ven determinados a actuar y se esfuerzan por conservarse". Ver también 2/8: "el derecho e institución de la naturaleza, bajo el cual todos los hombres nacen y, en lo que concierne la mayoría de ellos, viven, no prohíbe nada sino lo que nadie desea y que nadie quiere: no excluye ni los conflictos, ni los odios, ni la cólera, ni las astucias, ni absolutamente nada de aquello a lo que el apetito nos persuade".

${ }^{58}$ Con ello Spinoza respeta a su vez el principio de la universalidad del derecho natural.

${ }^{59}$ En su Carta L a Jarig Jelles, Spinoza expone en efecto la idea de una "continuación" (como ha sido llamada por los comentadores) del estado de naturaleza en el estado de civilidad, esto es: que lo que determina el derecho en ambos "estados" no es sino la potencia y las relaciones de fuerza que estas implican.

${ }^{60} \mathrm{Se}$ entiende así por qué Spinoza inscribe esta demostración en el seno de una investigación acerca del derecho natural del género humano.

${ }^{61}$ TP $2 / 15$.

${ }^{62}$ Ver TP $3 / 13$

${ }^{63} \mathrm{La}$ definición procede por propiedades. La definición genética se encuentra en TP 2/17.
${ }^{64}$ Cf. TP 6/1: "no puede ocurrir que el estado de civilidad sea totalmente disuelto".

${ }^{65}$ Según la Carta L a Jarig Jelles antes citada.

${ }^{66}$ Determinación extrínseca, claro está, puesto que el conatus no implica ningún tipo de negación capaz de limitarlo intrínsecamente. Y será el análisis de este límite (es decir la generalización de la exterioridad de las fuerzas causales, lo que Spinoza llama "la fortuna") el que nos llevará a la necesidad de concebir una tendencia opuesta operando en sentido contrario, el del acuerdo de las potencias o estado de civilidad.

${ }^{67}$ Coincidimos plenamente con la lectura matheroniana de las tres formas de Estado, Op. Cit. (1969), cap. 11.

${ }^{68} \mathrm{Si}$ el límite del estado de naturaleza es la negación misma de la potencia del hombre, el límite de la tendencia opuesta nos parece ser la razón, en la medida en que expresa la "verdadera potencia de actuar del hombre"; cf. la demostración de la proposición 52 de la Ética IV.

${ }^{69}$ Cf. por ejemplo, TP 3/3.

${ }^{70} \mathrm{TP} 3 / 3$

${ }^{71}$ La unidad de estas dos tendencias es determinada por la potencia de la multitud en la medida en que corresponden, en sus límites respectivos y opuestos (esto es: el grado cero de la existencia del conatus para el estado de naturaleza y el modo de vida racional para el estado de civilidad), los límites de la potencia de actuar del hombre (desde el más bajo hasta el más alto).

${ }^{72}$ Y la disminución de la una lleva consigo la disminución de la otra.

${ }^{73}$ Como dice Spinoza, sólo un afecto puede contrariar a otro afecto; cf. Ética, IV, P 7. 